\title{
Observations on the systemic effect of topical clobetasol propionate (Dermovate)
}

\author{
J A CARRUTHERS, P J AUGUST, R C D STAUGHTON
}

British Medical fournal, 1975, 4, 203-204

\section{Summary}

Topical application of clobetasol propionate in a strength of $0.05 \%$ in cream or ointment (Dermovate) suppressed the hypothalamic-pituitary-adrenal axis in both normal people and patients with diseased skin. In normal people the 9 am serum cortisol level was suppressed when between 45 and $90 \mathrm{~g}$ was applied weekly. Insulin stress test results in patients with diseased skin showed an abnormally small response after long-term application of similar amounts. We conclude that long-term administration should be restricted to less than $50 \mathrm{~g}$ a week.

\section{Introduction}

Clobetasol propionate, a new fluorinated topical corticosteroid, is widely used in both hospital and general practice in a strength of $0.05 \%$ in a cream or ointment base (Dermovate). It appears to be the most potent topical corticosteroid available. ${ }^{1}$ Adverse reactions to its use have included iatrogenic Cushing's syndrome, ${ }^{2}$ hypothalamic-pituitary-adrenal (HPA) axis suppression, $^{345}$ and the precipitation of generalised pustular psoriasis, ${ }^{\circ}$ which are well known complications of treatment with systemic corticosteroids. ${ }^{7}$ These problems prompted an attempt to quantify the effects of the preparation on the HPA axis in both normal people and patients with skin disease.

\section{Materials and methods}

Normal people-male volunteers aged 22 to 30 years applied clobetasol propionate cream daily either to the whole body, excluding head, axillae, and genitalia (approximately $90 \%$ of the body surface area), or to the limbs alone (approximately $50 \%$ of the body surface area). Either $45 \mathrm{~g}$ or $90 \mathrm{~g}$ or $175 \mathrm{~g}$ was used weekly (a quarter, half, or whole 25-g tube daily). Blood was taken between 9 and 930 am each day for estimation of serum cortisol by a competitive binding technique $^{8}$ that gives true readings for cortisol even in the presence of clobetasol propionate.

Patients-Insulin stress tests were performed on 13 patients with eczema or psoriasis affecting $5-50 \%$ of the body surface area who had been using the cream or ointment preparation for 10 weeks to 18 months. In the test ${ }^{9}$ an intravenous injection of insulin $(0 \cdot 1 \mathrm{IU} / \mathrm{kg}$ body weight) provokes a hypoglycaemia of less than $1.67 \mathrm{mmol} / \mathrm{l}$ $(30 \mathrm{mg} / 100 \mathrm{ml})$. This is an adequate stimulus for a maximal rise in serum cortisol to occur. The test measures the corporate integrity of the HPA axis.

\section{Results}

NORMAL PEOPLE

Two of the volunteers applied $45 \mathrm{~g}$ clobetasol propionate weekly to the whole body, and a further two applied this amount to the limbs only. In all cases the serum cortisol levels remained normal (fig 1).

Department of Dermatology, St Thomas's Hospital, London SE1 7EH J A CARRUTHERS, MA, MRCP, registrar P J AUGUST, MB, MRCP, senior registrar R C D STAUGHTON, MA, MRCP, registrar
Three volunteers applied $90 \mathrm{~g}$ clobetasol propionate cream weekly to their limbs (fig 1). In two the serum cortisol was completely suppressed by the eighth day; they then extended application of this amount to the whole body for a further week and suppression persisted. The third volunteer failed to show suppression and had a normal serum cortisol level throughout. In his case the experiment was repeated with identical results. Two further volunteers applied the cream to the whole body from the outset and also showed profound adrenal suppression. Fig 2 shows serial cortisol levels for one of these. The levels of the other rose, despite continued application, when he underwent an episode of stress associated with the delivery of his wife's first child.

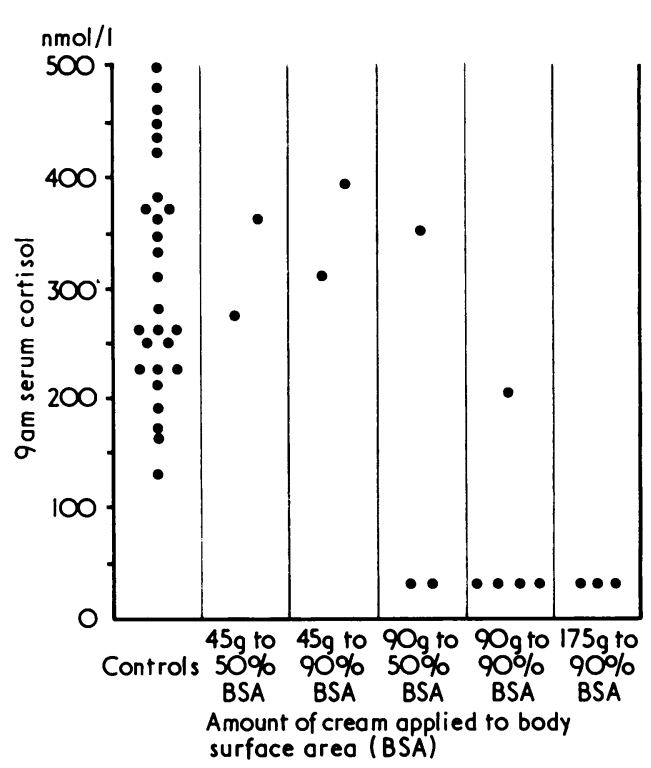

FIG 1-Lowest 9 am serum cortisol levels during application of clobetasol propionate cream in normal people.

Conversion: SI to traditional units-Cortisol: $1 \mathrm{nmol} / \mathrm{l}$ $\approx 0.036 \mu \mathrm{g} / 100 \mathrm{ml}$.

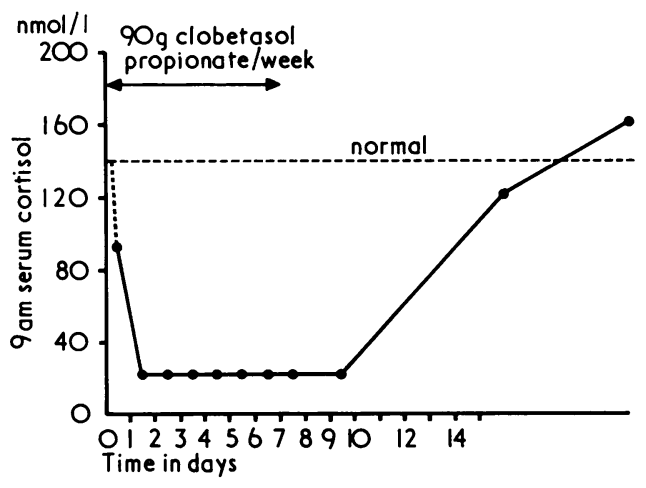

FIG 2-Response of one normal person to application of $90 \mathrm{~g}$ clobetasol propionate cream weekly to whole body.

Three volunteers applied $175 \mathrm{~g}$ of cream to the whole body (fig 1), which rapidly suppressed the serum cortisol levels in all three. One became feverish on the fifth day of application, and his serum cortisol returned to normal. In the other two the cortisol level returned to normal within one to four days of stopping application. 
PATIENTS

Figs 3 and 4 show a gradual reduction in the resting and stress cortisol levels respectively in the patients with increasing amounts of clobetasol applied. The lower limits of normal for these values were crossed when $50-100 \mathrm{~g}$ was applied weekly. One patient using only $40 \mathrm{~g}$ weekly had a reduced peak response in the insulin stress test. He had eczema of the hands and feet with severe cutaneous atrophy and may thus have absorbed greater amounts of the preparation.

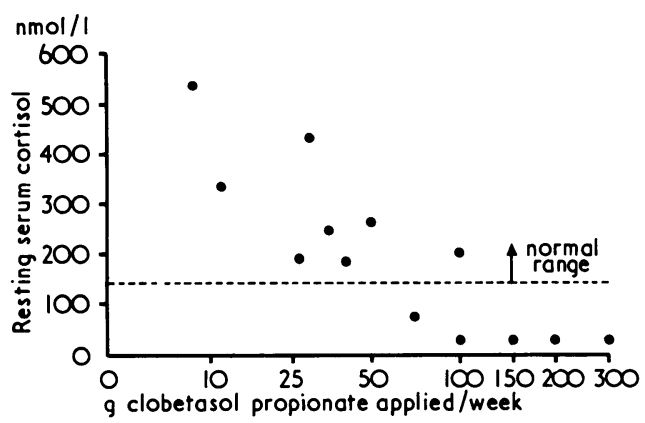

FIG 3-Resting 9 am serum cortisol levels after longterm use of clobetasol propionate.

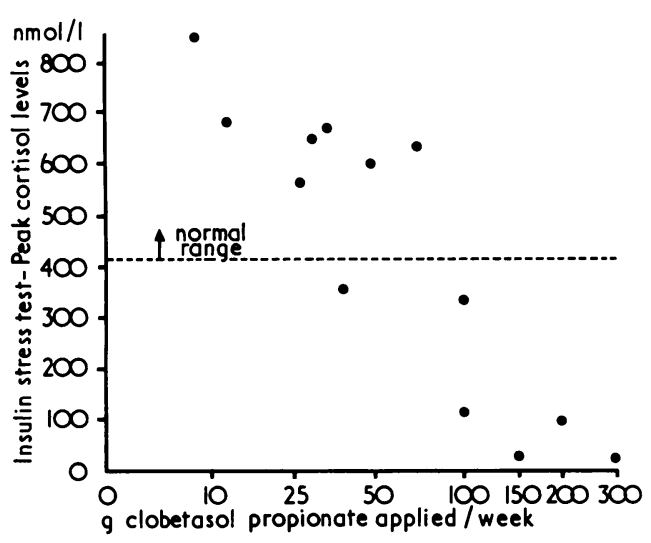

FIG 4-Peak cortisol levels during insulin stress after long-term use of clobetasol propionate.

\section{Discussion}

Our data agree with previous reports ${ }^{2-5}$ that topically applied clobetasol propionate in a strength of $0.05 \%$ (Dermovate) may cause profound suppression of the HPA axis. Normal people applying $45 \mathrm{~g}$ clobetasol propionate cream weekly did not show significant suppression, whereas all but one of those applying $90 \mathrm{~g}$ weekly showed profound suppression. This suggests that in most normal people the "safe" threshold for the amount applied weekly lies between 45 and $90 \mathrm{~g}$. We are unable to explain why one of the normal people failed to suppress at all with $90 \mathrm{~g}$ weekly and feel that this represents individual variation in the handling of the drug. Because of this we suspect that a few patients may be able to apply large amounts of the drug without developing features of Cushing's syndome. But, as our data on patients show, in most cases there appeared to be a linear relationship between the amount of the preparation applied and HPA axis suppression. Patients applying over $50 \mathrm{~g}$ weekly all had either a reduced 9 am serum cortisol level or a reduced peak insulin stress test level. Those using over $100 \mathrm{~g}$ weekly showed profound suppression and developed features of Cushing's syndrome. On withdrawal they suffered symptoms of adrenocortical insufficiency and developed pustular psoriasis.

Patients find preparations of clobetasol propionate gratifyingly effective for treating their stubborn dermatoses, especially psoriasis. They also appreciate the euphoriant effect, hence overenthusiastic application is particularly apt to occur. We conclude that patients should be warned against using more than $50 \mathrm{~g}$ a week. Their physicians should exercise as much caution with this cream as with systemic corticosteroids.

We thank Drs M M Black, H J Wallace, and G C Wells for permission to study their patients and for encouragement and helpful advice. The cortisol estimations and insulin stress tests were performed in Professor R V Brooks's department, and we are grateful for his and Dr Clara Lowy's help.

Requests for reprints should be addressed to: $\mathrm{Dr} J$ A Carruthers, St John's Hospital for Diseases of the Skin, Lisle Street, London WC2H $7 \mathrm{BJ}$.

\section{References}

1 Sparkes, C G, and Wilson, L, British fournal of Dermatology, 1974, 90, 197. 2 Staughton, R C D, and August, P J, British Medical fournal, 1975, 2, 419.

3 Tan, R S-H, Proceedings of the Royal Society of Medicine, 1974, 67, 719. 4 Feiwel, M, and Kelly, W F, Lancet, 1974, 2, 112.

5 Ortega, E, Burdick, K H, and Segre, E J, Lancet, 1975, 1, 1200.

${ }^{6}$ Boxley, J D, Dawber, R P R, and Summerly, R, British Medical fournal, 1975, 2, 255.

${ }^{7}$ Baker, H, and Ryan, T J, British fournal of Dermatology, 1968, 80, 771.

${ }^{8}$ Murphy, B E P, Fournal of Clinical Endocrinology and Metabolism, 1967, 27, 973.

Landon, J, Wynn, V, and James, V H T, fournal of Endocrinology, 1963, $27,183$.

\section{Infusion apparatus for parenteral nutrients}

The use of parenteral nutrition is achieving wide acceptance in many acute medical and surgical situations. To provide total parenteral nutrition for seriously ill patients the infusion of several nutrient solutions simultaneously may be required to provide daily metabolic requirements. Numerous studies have confirmed that the concomitant use of amino-acids with carbohydrate or fat emulsion provides a utilizable anabolic protein source for parenteral nutrition regimens. ${ }^{1}$ Increased efficiency of a parenteral diet is achieved when the calories are provided by both carbohydrate and fat, ${ }^{2}$ and optimal metabolic usage requires that carbohydrates, potassium, and amino-acid sources be administered simultaneously. ${ }^{3}$ " Many ill patients lose abnormal amounts of body fluids, and often require additional water and electrolyte supplements, together with vitamins and minerals. In patients with high metabolic demands, insulin and glucose regimens provide a valuable additional approach to the problem. ${ }^{5}$ The problerrs of chemical incompatibility between these various solutions and the risks of infection when such solutions are mixed have restricted the choice of suitable regimens available to clinicians. We describe an apparatus designed to overcome the problems of multiple intravenous fluid infusions.

\section{Design of Apparatus}

The system we have developed (see fig) allows great flexibility in prescribing intravenous solutions for seriously ill patients, whose metabolic requirements may be constantly changing. Though any combination of solutions can be used with this apparatus within the limitations of chemical compatibility, we describe a typical regimen for complete intravenous nutrition which has proved satisfactory in practice.

Bottles 1 and 2 contain amino-acid solutions and a calorie source respectively. The following solutions have been used concurrently and found to be compatible: amino-acid solutions-Aminoplex-14, Vamin, Trophysan, and Aminosol; calorie solutions-sorbitol, hypertonic glucose, fructose, and Intralipid. Bottle 3 contains normal saline or dextrose $5 \%$, with additional potassium supplements and multivitamin solutions as required. Bottle 4 